\title{
Learning to Think Slower: Review of Thinking, Fast and Slow by Daniel Kahneman (2011)
}

Samuel L. Tunstall

Michigan State University, stunstal@trinity.edu

Patrick N. Beymer

Michigan State University, beymerpa@msu.edu

Follow this and additional works at: https://digitalcommons.usf.edu/numeracy

Part of the Cognition and Perception Commons, Cognitive Psychology Commons, and the Science and Mathematics Education Commons

\section{Recommended Citation}

Tunstall, Samuel L., and Patrick N. Beymer. "Learning to Think Slower: Review of Thinking, Fast and Slow by Daniel Kahneman (2011)." Numeracy 10, Iss. 2 (2017): Article 16. DOI: http://doi.org/10.5038/ 1936-4660.10.2.16 


\title{
Learning to Think Slower: Review of Thinking, Fast and Slow by Daniel Kahneman
} (2011)

\author{
Abstract \\ Daniel Kahneman. Thinking, Fast and Slow (New York, NY: Farrar, Straus and Giroux) 499 pp. ISBN \\ 978-0374275631.
}

As an expansive review of Kahneman and others' work over the past half-century in understanding human decision-making, Thinking, Fast and Slow provides Numeracy readers much to consider for both pedagogy and research. In this review, we outline Kahneman's core argument-that humans use both rash (emotional) System 1 thinking and slow (logical) System 2 thinking-then discuss how such systems might be addressed in a quantitative literacy classroom.

Keywords

psychology, decision-making, risk, quantitative literacy, heuristics, biases

\section{Creative Commons License}

\section{(c) (i) (9)}

This work is licensed under a Creative Commons Attribution-Noncommercial 4.0 License

\section{Cover Page Footnote}

Samuel Luke Tunstall is a doctoral student in mathematics education and University Distinguished Fellow at Michigan State University. His research interests include quantitative literacy, critical discourse analysis, and the sociology of education.

Patrick N. Beymer is a doctoral student in educational psychology and educational technology at Michigan State University. His research interests focus on the relationships between student decisionmaking, emotions, and engagement. 


\section{Overview}

In Thinking, Fast and Slow (TFaS), Daniel Kahneman (2011)—Nobel Laureate and one of psychology's preeminent scholars - weaves together decades of research that he and others completed on how humans ${ }^{1}$ make decisions under uncertain conditions. Kahneman dedicated his book to now-deceased Amos Tversky, a longtime friend and colleague of similar influence in the discipline, crediting Tversky throughout the book as a key research wingman to whom his contributions to psychology are inextricably linked. Not surprisingly, those familiar with Kahneman and Tversky's (1974) classic article "Judgement Under Uncertainty" - which has just over 40,000 citations on Google Scholar at the time of this writing - will find themselves in familiar territory in reading TFaS, given that Kahneman's research career revolved around related issues. Familiar heuristics from the 1974 piece, including the representativeness, availability, and anchoring heuristics, make appearances throughout the book, but they do not comprise the central focus. Rather, Kahneman introduces two characters as metaphors for how the mind works, calling them System 1 and System 2, responsible for fast (intuitive and emotional) thinking and slow (deliberative and logical) thinking, respectively. These characters serve as the two protagonists in Kahneman's exposition, which spans from his Nobel Prize-winning work on prospect theory (Kahneman and Tversky 1979), to the ways in which we remember painful or happy events.

That Kahneman calls Systems 1 and 2 characters is evocative of the book's colloquial style, which is aimed at a general audience rather than those anchored to any specific discipline. As opposed to a textbook, TFaS is eminently accessible - a hallmark first resource for readers interested in cognitive biases and the story of the research behind their "discovery." However, the book is extensive, and it represents one scholar's curation of how the mind works; this story is Kahneman's, and it should not be taken as a universal account on the subject matter. Given the expansive scope of the book (the paperback version is 499 pages), this review cannot summarize the book in its entirety, making it difficult to generalize what one might get out of the book. Every reader's unique disciplinary background and life experiences will inevitably influence what insights or questions she or he takes away. Like Numbers and Nerves: Information, Emotion, and Meaning in a World of Data (Slovic and Slovic 2015), which was reviewed last year for Numeracy (Kelly 2017; Tunstall 2017), TFaS leaves one with more questions than answers. In this review, we summarize the core of Kahneman's book, then present salient issues and themes the Numeracy community might pick up for future teaching and research.

\footnotetext{
${ }^{1}$ A critique one could readily make of the book is that Kahneman does not devote space to the generalizability of the research he and others have done. Most of the research was done on U.S. college students, yet is generalized to describe how humans, broadly speaking, make decisions.
} 


\section{Two Characters and Two Species}

Imagine being asked "Should recreational marijuana be legalized?" by a colleague in the office breakroom. It is likely that you would have a gut reaction-a yes or no in mind-in responding. This gut reaction is the character of System 1 at play, driven effortlessly by our values and beliefs, and subject to the myriad pitfalls that Kahneman presents throughout the book. The consideration of other factors surrounding the issue of recreational marijuana, such as externalities, policy specifics, and so on, would be the task of System 2 if we were inclined to consciously engage it on the matter, perhaps discussing the issue in detail with the colleague. A central component of Kahneman's argument in the book is that, more often than not, System 1 is "correct" and System 2 is not needed; however, System 1 can be responsible for decisions that are not at all within our best interests. For instance, if we asked several individuals the question "Is Steve more likely to be a gambler, or a gambler with a drinking problem?" they would likely choose the latter option-an example of System 1's susceptibility to the conjunction fallacy. Of course, if we were social workers interviewing Steve and he admitted being a gambler, we would be correct in also asking if he drank alcohol consistently. The bulk of TFaS is to describe many of the ways in which System 1 can engender mistakes. In Table 1 below, we include a sampling of the heuristics and biases discussed. Of course, these are not exhaustive of what Kahneman discusses.

Table 1

Sampling of Biases and Heuristics from $\mathrm{TFaS}$

\begin{tabular}{cll} 
Bias or heuristic & Example in relation to quantitative literacy \\
\hline $\begin{array}{c}\text { Illusion of validity, } \\
\text { Chapter 20 }\end{array}$ & $\begin{array}{l}\text { Description } \\
\text { model or source of knowledge is } \\
\text { more valid than one which is not }\end{array}$ & $\begin{array}{l}\text { An individual deciding where to invest money } \\
\text { may believe that a mutual fund from Fidelity } \\
\text { Investments is more profitable than a similar } \\
\text { fund like the S\&P 500 }\end{array}$ \\
$\begin{array}{l}\text { Anchoring, } \\
\text { Chapter 11 }\end{array}$ & $\begin{array}{l}\text { We tend to make inferences or } \\
\text { estimates differently depending } \\
\text { on how the issue was initially } \\
\text { brought up }\end{array}$ & $\begin{array}{l}\text { If a student is asked to estimate their } \\
\text { anticipated salary upon graduating college, } \\
\text { their response would be different if-for } \\
\text { example-the prompt was initially preceded } \\
\text { by a statement such as "most graduates tend to } \\
\text { make above-average salaries" }\end{array}$
\end{tabular}

Loss aversion (a We tend to weigh potential losses hallmark element as more important than equivalent

of prospect potential gains when making theory), Chapter 26

Duration neglect, Chapter 35 decisions

When recalling an experience, the duration of the experience is not as important as how pleasant or unpleasant parts or the entirety of the experience was
Other things equal, students are more likely to pick a credit card with no annual fee than one with an annual fee and benefits that make up for the fee

A student with one horrible interaction with a professor is more likely to retrospectively report the semester being horrible, than is a student who had frequent mildly negative, but unmemorable interactions with the professor 
As one might imagine, some of these biases from Table 1 could have serious repercussions for individuals, companies, and governments, among other entities. The implication is that it is imperative that we aim to be aware of our proneness to mistakes. As Kahneman contemplates in his concluding remarks: "The way to block errors that originate in System 1 is simple in principle: recognize the signs that you are in a cognitive minefield, slow down, and ask for reinforcement from System 2" (p. 417). This task is not easy, of course, and Kahneman is quick to point that out, noting that it is much easier to observe others walking into mistakes than it is to see the issues in one's existing judgment. Such limited foresight leads Kahneman to his critique of the traditional assumption of economists that humans are rational agents.

To that end, in Part Four of the book (entitled "Choices"), Kahneman broaches the salient disconnect, or paradigmatic divide, between economists and psychologists, in that the former group tends to assume humans make decisions that are in their best interests and internally consistent, whereas many in the latter group-himself included-suggest that such assumptions are not true. Using the terminology of Richard Thaler (co-author of the bestselling book, Nudge), he calls rational humans Econs, and fallible humans Humans - two species that highlight the disciplinary divide (Thaler and Sunstein 2008). This disconnect troubles Kahneman to the extent that he devotes space in the text to discuss the divide and to critique liberalism, especially as espoused by Milton Friedman and colleagues of the Chicago School of Economics. Kahneman notes that merely describing humans as irrational is unproductive. In one of our favorite quotes from the book, he writes: "I often cringe when my work with Amos is credited with demonstrating that human choices are irrational, when in fact our research only showed that Humans are not well described by the rational-agent model" (p. 411). Though at times Kahneman's writing may feel like a polemic on human reasoning - a critique we levy only because of our optimistic attitude toward students' thinking - it is worth noting that Kahneman does have a positive outlook on the Humans species.

\section{Thoughts for the Numeracy Community}

Moving beyond the content of the book, there are a number of a ways in which educators might utilize the content of $T F a S$ in a quantitative literacy classroom. An easy means of broaching these issues in the classroom is to discuss the biases and heuristics directly. We can readily imagine an instructor devoting some time each week, or during targeted lessons, to various heuristics and biases discussed in the book, relating them to mathematical principles as appropriate. For example, in discussing the concept of the correlation coefficient, one could bring up Chapter 20's notion of the Illusion of Validity in describing how mutual funds rarely - on average at least - outperform the S\&P 500 over the course of any single year. 
An additional idea is that one could devote a week (or more) to the mathematics of happiness, discussing existing operationalizations of the construct and how one might quantify the notion of a happy life. This discussion could build from Chapters 35 through 38 of Kahneman's book, where he gives several examples of measuring subjective constructs using basic graphs. In Figure 1, we provide an amusing sample graph that could bring out conversation in the classroom. As Kahneman describes in these chapters, research has shown that the way one retrospectively describes an event is not necessarily the "logical" sum of prior related events; that is, for example, in evaluating the enjoyment of one's marriage,

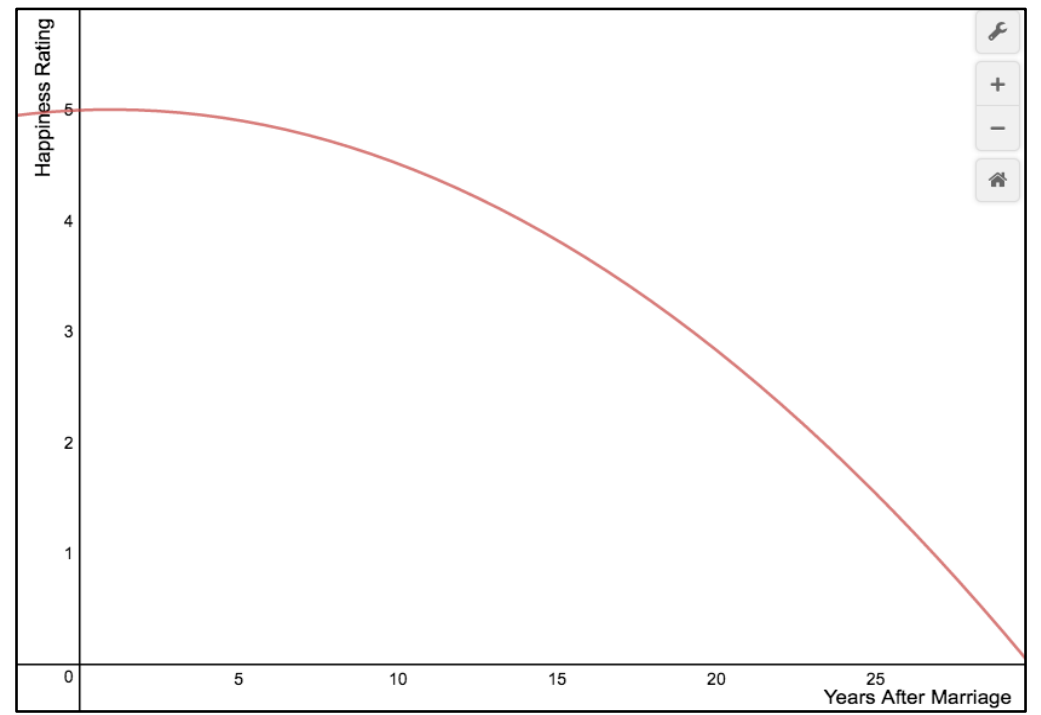

Figure 1. Graph relating an individual's happiness rating over time after marrying, discussed in the text.

it is not necessarily the sum of all the times one was happy minus the times one was unhappy. In the case of Figure 1, the individual in the graph might note that the marriage was a complete disaster, despite the overall happiness throughout its span over 30 years. This dynamic brings the issue of logical conclusions directly to the fore, as there is an ostensible mismatch between human behavior and mathematical necessity in this case and in many examples in the book. Kahneman errs on the side of calling such mismatches on the part of humans illogical, which - though we see where he is coming from-may be an area for debate. Throughout the book, Kahneman makes normative claims about how humans should behave if they were logical. Their failure to make logical choices-often a consequence of System 1's doing-is most often positioned as a problem. Hence the reason for the book.

Beyond how we might work to make students cognizant of Systems 1 and 2, we also see promise in framing aspects of a course using the insights of prospect theory and other related work Kahneman describes. A key idea from prospect theory (Kahneman and Tversky 1979) is that while humans like to win, they prefer to avoid losses more so than achieve equivalent gains. One could readily incorporate this dynamic into one's syllabus or assessment. For instance, studies 
have shown that when grading scales are framed in terms of gains (0 to 100) rather than losses (100 to 0), students show increased motivation and achievement (Bies-Hernandez 2012). In a related manner, Smith and Smith (2009) found that using a grading scale out of 600 points increased student motivation, confidence and performance, and anticipated effort in class as compared to a grading scale out of 100 points or 100 percent. This study suggests that the way an instructor uses framing - or different ways of presenting a single idea (Tversky and Kahneman 1981) - in a syllabus may have implications for adaptive student outcomes. Framing may also be used as a starting point in the classroom to show students how news articles using statistics can present stories in a positive or negative light (i.e., gains or losses). Tversky and Kahneman (1981) discuss how framing in this regard can lead to preference reversals.

Moving beyond the classroom or syllabus, we can think of several research questions that Numeracy readers might be interested in. For example, to what extent is it the responsibility of courses with a quantitative literacy designation to account for and "correct" the heuristics and biases that Kahneman raises in TFaS? The mathematics classroom is typically viewed as outside the purview of judgment and decision-making, but Kahneman makes clear that our actions when faced with quantitative information are often led by System 1, rather than System 2 , and thus that we should be attuned to such biases if we are to have a chance at correcting them. Another area ripe for exploration, as alluded to in the examples we mentioned, is the way in which we might use framing in the classroom (and perhaps institutionally as well). Although research suggests that framing can be used in the classroom to elicit adaptive student outcomes, researchers may still wish to explore this area in more detail. For example, researchers may find interest in examining how an instructor can use framing in a syllabus in other ways besides grading scales to evoke positive student behavior.

No doubt, there are many more questions that interested readers will likely raise from TFaS. Indeed, we imagine that-with another read of the book-we would take away new insights and questions. One thing that remains clear is that Numeracy readers should read Kahneman's expansive work. Not only is it an essential read for those not rooted in psychology but interested in its insights, it is at once both accessible and brimmed with historical commentary unlikely to be found in any research article.

\section{References}

Bies-Hernandex, N. J. 2012. "The Effects of Framing Grades on Student Learning and Preferences." Teaching of Psychology 39(3): 176-180. https://doi.org/10.1177/0098628312450429.

Kahneman, D., and A. Tversky. 1979. "Prospect Theory: An Analysis of Decision Under Risk." Econometrica 47(2): 263-291. https://doi.org/10.2307/1914185.

Kahneman, D. 2011. Thinking, Fast and Slow. Farrar, Straus and Giroux. 
Kelly, A. 2017. "Harnessing the Power of Emotion for Social Change: Review of Numbers and Nerves: Information, Emotion, and Meaning in a World of Data by Scott Slovic and Paul Slovic (2015)." Numeracy 10(1): Article 9. https://doi.org/10.5038/1936-4660.10.1.10.

Slovic, S., and P. Slovic, eds. 2015. Numbers and Nerves: Information, Emotion, and Meaning in a World of Data. Corvallis, Oregon: Oregon State University Press.

Smith, J. K., and L. F. Smith. 2009. "The Impact of Framing Effect on Student Preferences for University Grading Systems." Studies in Educational Evaluation 35(4): 160-167. https://doi.org/10.1016/j.stueduc.2009.11.001

Thaler, R. H., and C. R. Sunstein. 2008. Nudge: Improving Decisions about Health, Wealth, and Happiness. Yale University Press.

Tunstall, S. L. 2017. "Connecting Numbers with Emotion: Review of Numbers and Nerves: Information, Emotion, and Meaning in a World of Data by Scott Slovic and Paul Slovic (2015)." Numeracy 10(1): Article 9. https://doi.org/10.5038/1936-4660.10.1.9.

Tversky, A., and D. Kahneman. 1974. "Judgment under Uncertainty: Heuristics and Biases." Science 185 (4157): 1124-1131. https://doi.org/10.1126/science.185.4157.1124.

Tversky, A., and D. Kahneman. 1981. "The Framing of Decisions and the Psychology of Choice.” Science 211 (4481): 453-458. https://doi.org/10.1126/science.7455683. 